\title{
A Systematic Literature Review and Analysis of Unemployment Problem and Potential Solutions
}

\author{
Safaa Alkatheri \\ Department of Information Systems \\ Faculty of Computing and IT \\ King Abdulaziz University Jeddah, Saudi Arabia
}

\author{
Abdullah Saad AL-Malaise AL-Ghamdi \\ Department of Information Systems \\ Faculty of Computing and IT \\ King Abdulaziz University Jeddah, Saudi Arabia
}

\begin{abstract}
Investments in training and education are one of the most important things that can help people acquire the required skills and knowledge for employment. However, in this changing environment, with a lot of emerging technologies, the major challenges facing many people is keeping up with the needed market skills and investing in upskills. This paper presents a comprehensive literature review using a content analysis approach to investigate the reasons for the unemployment problem across many countries and identifies proposed solutions and suggestions to handle this problem and particularly the problem of skills mismatch. The results indicated that the previous solutions were inadequate as they used reactive strategies, thus, people cannot respond quickly to change in the market and acquire the required skills immediately.
\end{abstract}

\section{Keywords}

Mismatch, skills gap, skills mismatch, unemployment.

\section{INTRODUCTION}

The 21st century workplace is unique, thus, people who have both adequate and demanded skills can easily get appropriate jobs. On the other hand, many people still do not have jobs due to a lack of the needed skills or the impact of a skills mismatch problem, which leads to unemployment in many countries [1]. The numbers of unemployed vary from one country to other. Table 1 shows the unemployment rate in various countries

Moreover, in the study of [2], the concept of unemployment is defined based on a standard and a national definition. The standard definition defines it as the number of the labor force who are without work, but seeking employment. While the national definition refers to it as the total of individuals not working. It is also defined as the people who are not working, but are willing and able to work [3]. Further, it is defined as the number of people from ages 15 to 65 years which are unemployed and seeking work [4].

Regardless of the specific definition, all definitions of unemployment agree that seeking jobs and the ability to work are the main characteristics of unemployed people. Since unemployment leads to negative economic, social, and security outcomes [5], this paper aims to identify the causes of this problem, the impact of skills mismatch problem on the rate of unemployment, and the proposed solutions and suggestions to tackle it across many countries.
Table 1: Summary of Some Unemployment Rate [1] [6]

\begin{tabular}{|c|c|c|c|}
\hline Country Name & 2015 & 2016 & 2017 \\
\hline West Bank and Gaza & 25.82 & 26.89 & 27.4 \\
\hline South Africa & 25.16 & 26.55 & 27.33 \\
\hline Lesotho & 26.978 & 27.78 & 27.25 \\
\hline Eswatini & 26.33 & 26.35 & 26.4 \\
\hline Bosnia and Herzegovina & 27.69 & 25.06 & 25.56 \\
\hline Mozambique & 25.3 & 25.15 & 25.05 \\
\hline Namibia & 19.59 & 23.35 & 23.33 \\
\hline Macedonia, FYR & 26.07 & 23.72 & 22.38 \\
\hline Greece & 24.9 & 23.54 & 21.49 \\
\hline St. Lucia & 24.1 & 21.26 & 20.98 \\
\hline
\end{tabular}

Considering the potential outcomes associated with unemployment, this is an undesirable phenomenon. This problem is addressed through three questions: 1) What are the causes of the unemployment problem? 2) How is mismatch defined and measured? 3) What are the policies and practices that aim to mitigate unemployment? The systematic literature review is used to answer these questions in order to present an integrated summary of the existing body of knowledge.

This paper begins in Section 2 by describing the literature search strategy. Section 3 explains the causes of the unemployment problem. Section 4 discusses how mismatch is defined and measured. The policies and practices that aim to mitigate unemployment are presented in section 5. In section 6 , we discuss the results of the literature review, and finally, the conclusion and future work are given in section 7 .

\section{METHOD}

For the systematic literature review, inclusion and exclusion criteria are set to narrow the research to a set of studies for comprehensive analysis. The inclusion criteria were: 1) They are published between 2000 and 2019,2) they were published in peer-reviewed academic journals, 3) they were written in the English language, 4) they were original or empirical studies, and 5) the studies are focused on the unemployment problem. The exclusion criteria were as the followings: 1) Excluding the duplicated studies. 2) Excluding non-peerreviewed studies. 3) Excluding non-English studies. 4) Excluding theoretical and conceptual studies. 5) Excluding studies that did not focus on unemployment.

The literature search was limited to 2000-2019 since the technology became a big issue after 2000 as a result of the sudden rise of it. Consequently, this resulted in an increasing unemployment rate, and the relationship between inflation and unemployment followed the Phillips curve. Furthermore, the systematic review is limited to publications in English due to a lack of facilities for translation. Moreover, only original or 
empirical studies that published in peer-reviewed academic journals were considered. Finally, studies that did not mainly concentrate on the unemployment problem were excluded, such as employment mismatch studies as these studies do not answer the research questions. All the previous criteria were used to improve the quality of our systematic literature review.

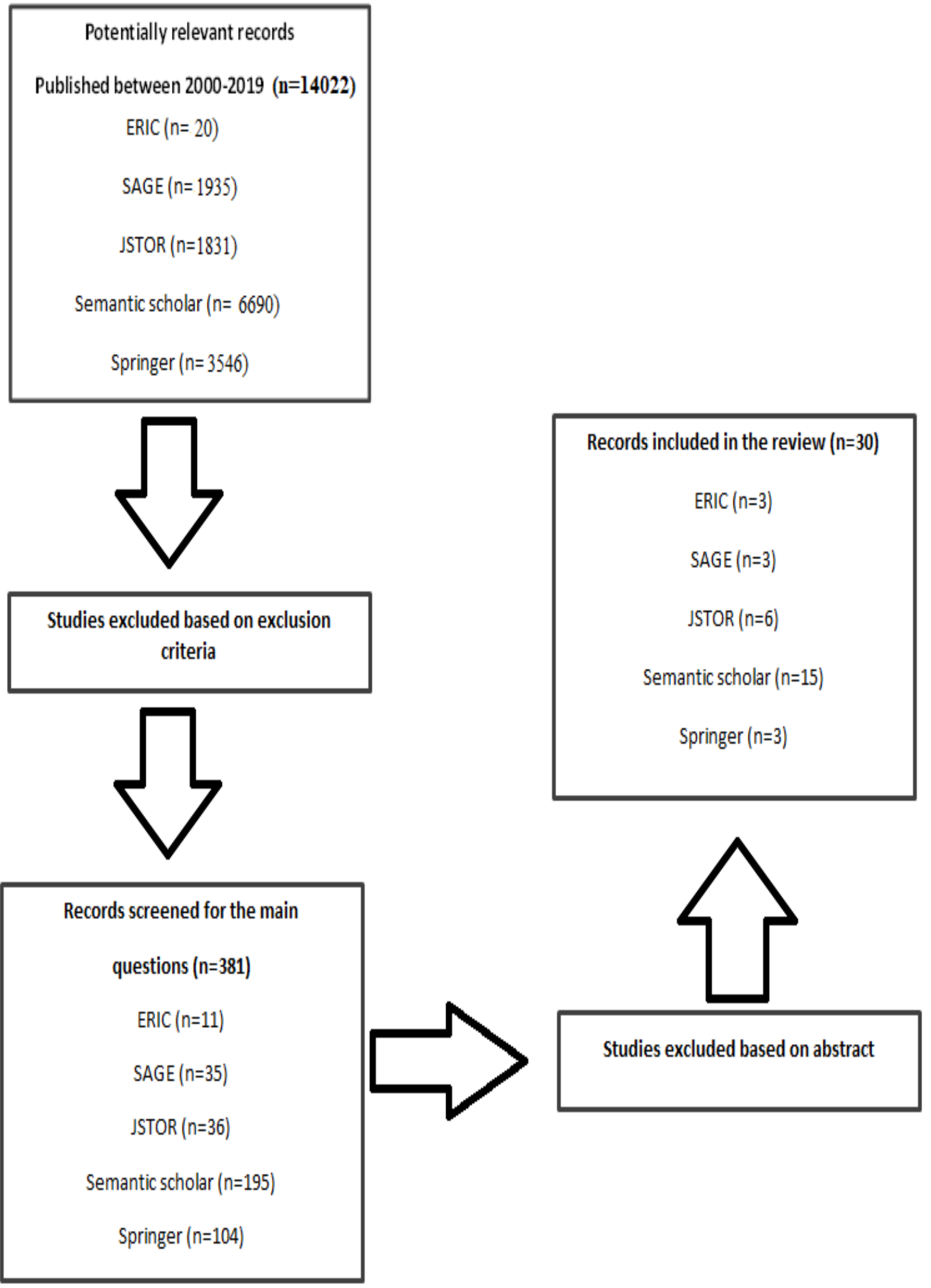

Fig 1: The selection process of literature review 
The systematic search used a collection of keywords, namely, "unemployment", "mismatch", "Mismatch skills", "Educational mismatch", "Skills gap", "Demand skills", "Machine learning", "Supply skills", "prediction", "forecasting". The search was performed in the following search engines: ERIC, SAGE, JSTOR, Semantic Scholar, and Springer. Those search engines were used as the main search engines as they provide access to more than 1,000 scientific journals. Fig 1 provides an overview of the processes of selecting the literature review (see Appendix A for the exact combination of search keywords and the specific search criteria).

\section{THE MAIN CAUSES OF THE UNEMPLOYMENT PROBLEM}

The literature discusses unemployment as being caused by many things. Fig 2 shows the dimensions of the unemployment problem.

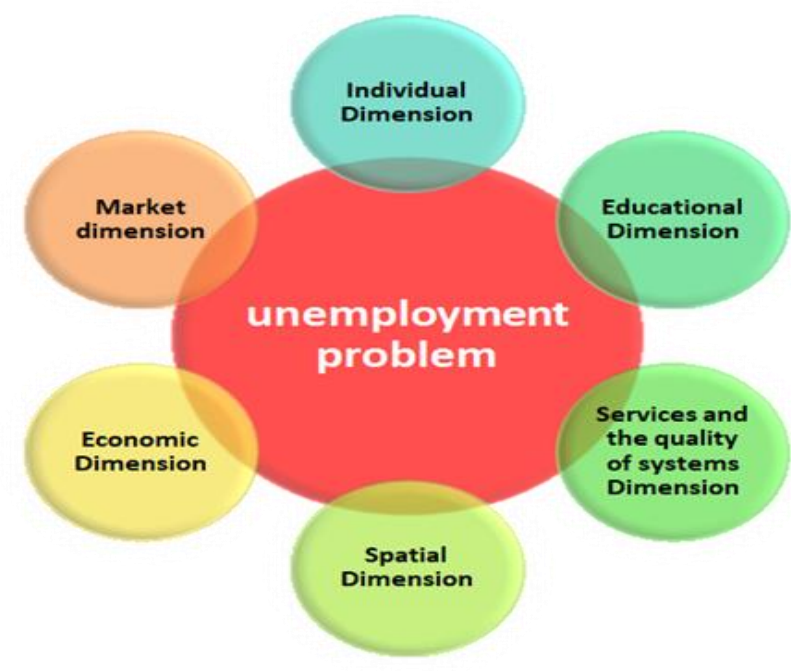

Fig 2: Dimensions of unemployment problem

Regarding the educational dimension, one of the causes of unemployment is the field of study [2] [7]. The student should know what the careers of their field of study are and what the market needs in relation to their study. Without doing that, this will lead to market saturation in some fields and a lack of skilled labor in others. For example, the study of [7], in South Africa, found that specific majors of graduated students were affected the time to find employment, and therefore, may cause unemployment problems. Consequently, it demonstrates that graduated students in the areas of human resources, industrial psychology, labor relations management, public administration, public management, and politics must wait a long time before finding a job after graduation. In particular, the wait time is about 19 months for graduated students in the fields of public management, public administration, and politics, compared to only 10.5 months in human resources, industrial psychology, and labor relations. On the other hand, graduated students in the fields of accounting, math, education, and health have the shortest average wait periods.

Apart from the field of study, job skills mismatch is also mainly related to unemployment problem based the educational dimension. While an increasing number of universities have greater enrolment than in past decades, less attention is paid to their output quality in terms of balancing acquired skills with demanded skills. This has led to increasing the unemployment rate of graduated students, especially since the recession, as only a few graduated students possess required market skills [2] [8] [9] [10] [11] [12] [13] [14] [15] [16]. For example, this mismatch contributed to approximately one-third of the recent rise in US unemployment [9], as the greater number of mismatches happen at the educational level. Moreover, when the unemployment rate increases by $3 \%$, the percentage of mismatch is expected to increase by $30 \%$ in Norway [11]. In addition, one-ninth of the causes of unemployment during the great recession was due to skills mismatch in the Netherlands [15]. On the other hand, the study of [16] showed that a small rate of mismatch was related to both education and skills, while a larger rate was related to either education or skills only. In addition, it found that the relationship between education and skills mismatch was negative, which plays an important role in tackling this labor skills inefficiency. Further, the studies of [17] [18] [13] pointed out the competence level of graduated students as one of the causes of unemployment. Thus, the students might believe they have the required skills to satisfy the needed market skills, but the employers do not.

In terms of individual dimensions, the studies of [19] [8] showed that age was negatively related to unemployment. Thus, young people between 21 and 25 years have the highest unemployment rate. Therefore, for every one unit increase in age, unemployment is expected to be lower, for example, by $0.2 \%$ in Pakistan. Thus, the unemployment rate for adults is less than for the young. The reason behind this is the lack of acquired skills and experience in young people.

Moreover, gender is another cause of unemployment [8] [20]. It contributes to $39.5 \%$ of unemployment in educated females, compared to only $25.8 \%$ of educated males in Iran [8]. Unemployment among females is also higher in urban than in rural areas [20]. In addition, the study of [19] pointed out that single people are more unemployed than married, because married people often accept lower wages to do their liabilities after marriage. Furthermore, demographic youth bulges and housing discrimination have played roles in unemployment, especially among blacks in the central cities [20] [21]. Additionally, a lack of confidence and poor English communication skills are considered other factors that lead to unemployment, especially in countries that do not use English as a native language [2]. This cause supported by many studies such as [22] [23] [13].

As for the market dimension, supply and demand are pointed out as other important factors that affect unemployment [8] [24] [25]. Consequently, an increasing number of universities graduates do not match the jobs available. Moreover, the decrease in demanded skills causes an increase in the unemployment rate, especially when this decrease is more than the increase in qualified labor [25]. In addition, the people who possess specific outdated qualifications and skills are also unemployed as there is no demand for their expertise and they have not acquired new skills. This resulted from an inability to predict future market demand and a fast response to change [24]. Finally, being excluded from the labor market for many years was cited as the biggest barriers to work that is faced by long-term unemployment, as mentioned in study [18].

Regarding the economic dimension, there are a few studies, such as [20] pointed out that poor economic growth is one of the causes of unemployment, and the gross domestic product (GDP) is related to the unemployment rate, which results in an increase in poverty and low foreign investment [26]. 
About the services and the quality of systems dimension, there are two likely factors that lead to ineffective career guidance and counselling services, then leading to unemployment problem [2]. Those factors were the lacking of career guidance and counselling policy and the lacking of career counsellors [27]. Consequently, the governments should pay more attention towards career guidance and counselling services, as they help students choosing the careers that match the need of the market, and therefore reducing the probability of unemployment. Also, an ineffective labor market information system leads to having no knowledge regarding the works available, which then contribute to unemployment problem [2]. Therefore, the governments should strength this system and disseminate information about employers and the jobs status. In addition, a few studies pointed out that gaps in the employment policy may be leading to unemployment [2]. One of the challenges of employment was an imbalance between the policies and reality such as the imbalance between the supply and demand, new entrants in the labor market, freezing employment in the public sector, and lacking the needs analysis.

Apart from the services and the quality of systems dimension, the studies of [28] [15] showed that geographic mismatch is considered as one of the minor causes of unemployment. In particular, it can reduce the unemployment rate only by $5.3 \%$, and it did not increase since the great recession. Therefore, if the governments want to reduce the unemployment rate to the lower level, they have to solve other causes than this one.

Table 2 summarizes the findings of the main causes of unemployment problem across the world, and categorizes them into educational, individual, market, economic, services and the quality of systems, and spatial dimensions.

\section{MISMATCH DEFINITIONS AND MEASUREMENT}

The match between the labor supply and labor demand is necessary for society from one side, and companies as well as economy from the other side. The problem of mismatches may produce a lot of consequences on the level of the individuals, which leads to unemployment problem. Moreover, its consequences are extended to include wage penalties [29], job dissatisfaction [30], and so on. Mismatch has many types and measurements; this section describes them.

Table 2: Summary of causes of the unemployment problem

\begin{tabular}{|c|c|}
\hline $\begin{array}{c}\text { Causes of Unemployment } \\
\text { Problem }\end{array}$ & References \\
\hline \multicolumn{2}{|c|}{ Educational Dimension } \\
\hline The field of study & [2] [7] \\
\hline Job skills mismatch & $\begin{array}{c}2][8][9][10][11][12] \\
{[13][14][15][16]}\end{array}$ \\
\hline $\begin{array}{c}\text { Competence level of graduated } \\
\text { students }\end{array}$ & [13] [17] [18] \\
\hline \multicolumn{2}{|c|}{ Individual Dimension } \\
\hline $\begin{array}{l}\text { Lack of confidence and poor } \\
\text { communication skills }\end{array}$ & [2] [13] [22] [23] \\
\hline Age & [8] [19] \\
\hline Gender & [8] [20] \\
\hline
\end{tabular}

\begin{tabular}{|c|c|}
\hline Single people & {$[19]$} \\
\hline $\begin{array}{c}\text { Demographic youth bulge and } \\
\text { housing discrimination }\end{array}$ & {$[20][21]$} \\
\hline \multicolumn{2}{|c|}{ Market Dimension } \\
\hline Supply and demand & {$[8][24][25]$} \\
\hline $\begin{array}{c}\text { excluding from the labor } \\
\text { market }\end{array}$ & {$[18]$} \\
\hline \multicolumn{2}{|c|}{ Economic Dimension } \\
\hline Poor economic growth & {$[20]$} \\
\hline \multicolumn{2}{|c|}{ GDP } \\
\hline $\begin{array}{c}\text { Ineffective labor market } \\
\text { information system }\end{array}$ \\
\hline \multicolumn{2}{|c|}{ Services and the Quality of Systems Dimension } \\
\hline Gaps in the employment policy & {$[2]$} \\
\hline $\begin{array}{c}\text { Ineffective career guidance and } \\
\text { counselling services, }\end{array}$ & {$[15][28]$} \\
\hline \multicolumn{2}{|c|}{ Spatial Dimension } \\
\hline Geographic mismatch & {$[26]$} \\
\hline
\end{tabular}

Mismatches defined in study [31] as an imbalance between the job performed by people and their education and skills. Moreover, there are many types of mismatch that mentioned in the literature review. For example, the studies of [2] [11] [32] defined skills mismatch as an imbalance between the acquired skills from education and the needed market skills. Moreover, this mismatch measures the level of skill which classified into two categories; over-skilled and under-skilled [31]. Over-skilled means a person's skills are under-utilized in their job. However, under-skilled means the current work requires more skills from a person than their current skills.

Some types of these skills mismatch were defined in the literature as the followings: skill surplus which measures individual skills and job requirements, and it exists when individual skills exceed job requirements [2]. Also, skills gap that measured based on the difference between the attained skills and the job required skills [2]. Moreover, the vertical mismatch which based on the individual level of education and the job's required level [2] [31]. This type of mismatch is classified as under-education or over-education [31]. In the under-educated, the person has a low education level, while his/ her job requires more education. An over-educated person has a higher education level, but his/ her job requires less. Hence, this type of mismatch happens when a person with a high level of education is employed in a job that requires a low level of education and vice versa. In addition, horizontal mismatch which measured based on the type of education or skills for both individual and job [2] [31]. This mismatch exists when the type of education or skills is inappropriate for the job. Moreover, skill obsolescence which based on the relationship between previously used skills and required market skills, and then this type of mismatch happens when the previously used skills are not required in the market [2].

Apart from skills mismatch, there are also a few types of mismatch like geographic mismatch, which defined as an unwilling from the job seekers to move to another area with better job prospects [28]. Also, mismatch unemployment 
which referred to it as an imbalance between the distribution of vacancies and unemployed people [14]

\section{POLICIES AND PRACTICES TO MITIGATE UNEMPLOYMENT PROBLEM}

Education and training are one of the most important and expensive investments that governments make across the world [33] [34]. The highest return on investment value is obtained only when a match exists between job seekers and employers. In this section, a comprehensive literature review is made to build knowledge regarding the ways and policies that used or suggested to solve this problem.

There are many studies that have suggested solutions to solve the problem of skills mismatch. For example, the studies of [2] [26] suggested using entrepreneurship training as a longterm solution, so the students have to be trained on the ways of using their context to earn a living. Also, they suggested increasing the training opportunities, in some cases, to respond quickly to any change in the required skills. Moreover, the study of [19] suggested establishing small industries to employ the labors who have skills in handmade items. In addition, the studies of [19] [35] suggested launching an internship program and industrial training, so the students get experience side by side their education, also their generic and communication skills will increase, and the level of English language proficiency will improve. Consequently, the probability of rejecting them by employers will decrease. Additionally, the study of [7] proposed that the university courses have to be practical as possible to help the graduated in the job market, and therefore making the transition from education to work easier. For this, the government needs to enhance and augment teaching and learning throughout the educational system, and the governments should provide career guideline to students to bridge the gap between acquired and required skills. Moreover, the focus on the field of study for students must be made to bridge the effect of skills mismatch [19]. However, the majority of the fields of study reduce both short-term and long-term unemployment, but some of them were more effective in reducing short-term unemployment, which were education, engineering, health and welfare, and services and tourism [36]. On the other hand, some of them were more effective in reducing long-term unemployment which were sciences, biology and environment, computer use, and health and welfare.

Apart from a skills mismatch, to solve the problem of ineffective career guidance and counselling services, the study of [2] suggested training career counsellors in higher education institutions, as well as having counselling services available in all higher education institutions. On the other hand, to solve the problem of lacking the confidence and poor communication skills, the study of [2] recommended building English language learning centers to help people compete in the labor market both inside and outside their countries. To solve the problem of spatial mismatch, the study of [37] suggested facilitating spatial job accessibility that requires fewer skills. Consequently, the unemployment rate will decrease among less-educated native-born black, foreign-born Mexican, and foreign-born Vietnamese women. This is because they do not have adequate methods for searching jobs.

Turning to the general problem of unemployment, there are many studies that try to solve this problem. For example, the studies of [37] [18] [38] proposed facilitating the local access to employment services, job-search assistance, and counselling to facilitate physical bridges between people, jobs, and employers. Moreover, the study of [36] proposed having at least an academic degree to increase the chances of employment, and therefore, reducing both the short-term and the long-term unemployment. However, this impact different across the countries. In particular, the countries that have a positive relationship between academic degree and employment were Finland, Belgium, and the UK. While other countries, like Italy, Greece, and Portugal have a negative relationship between academic degrees and the probability of employment. The study of [20] emphasized investment in the sectors of agriculture, manufacturing, and education to create new jobs and develop skills. Also suggested was slowing down the grow of the youth population as it contributes to the largest percentage of unemployment in many countries such as in Iran [8] and in Pakistan [19]. In addition, the study of [12] emphasized on collaboration between universities and industries. Then, the industrialists have to participate in putting curricula, and teach students some important practical courses in their universities. In addition to that, the governments should force inside industries the policy that states not allowing to bring foreign expatriates in the skills that have native qualified people. The study of [39] proposed a project called BELLCURVE to modernize higher education to satisfy the skills market demand. This project takes feedback from academic and community to make it more efficient and effective. Moreover, the study of [26] proposed increasing foreign investment to enhance the growth and then reducing the unemployment rate. Additionally, the study of [15] emphasized fostering labor market mobility and encouraging schooling. This policy assumes that the jobs are already available in some sectors, while the other sectors suffer from the high number of unemployment. Consequently, fostering labor market mobility helps to achieve the labor market matches and decreases the unemployment rate in some sectors like information technology sector.

\section{DISCUSSION}

The most obvious findings to emerge from the analysis of literature reviews are that some causes of the unemployment problem are similar across many countries such as job skills mismatch, supply and demand, and the competence level of the graduated students. Whereas other causes are related to a few numbers of countries, such as ineffective labor market information system, gaps in the employment policy, and poor economic growth. Moreover, it is interesting to note that the job skills mismatch still makes a large contribution to the unemployment problem in many countries. Therefore, based on authors' knowledge, if this cause is solved by using effective methods, perhaps this will lead to a decrease in other causes of unemployment, or at least partially tackle some of them, since they believe other causes are interwoven with job skills mismatch and dependent on some others. Furthermore, contrary to expectations, all the previous solutions and suggestions which presented in the mentioned literature reviews did not invest the advanced technologies to solve this unemployment problem. Based on that, those solutions may have a long-term impact than short-term, since they may solve this problem reactively. On the other hand, advanced technologies may contribute to solve this problem proactively, and then they have a short-term impact. 


\section{CONCLUSION AND FUTURE WORK}

We conclude from the comprehensive literature review that the unemployment problem still exists in many countries across the world. This unemployment problem results from many causes, and some those causes have existed in many countries, while other causes are related to a few countries. Additionally, the mismatch problem was considered as one of the main causes of unemployment problem, since it contributed to unemployment in many countries as mentioned in Section 3. Therefore, Section 4 concentrated on mismatch by defining its types and measurements.

To answer the research questions, the studies from 2000 to 2019 were reviewed. Obviously, all those studies did not use advanced technologies such as machine learning to solve the unemployment problem; they used reactive solutions than proactive. As we live in circumstances, market fluctuation, and unforeseen conditions, such as economic fluctuation, inflation fluctuation, and so on, the authors believe that the reactive solutions are not suitable tools to solve this problem, as they cannot predict the market demand and response to change quickly. Based on that, further research should be undertaken to investigate the impact of using such advanced technologies as machine learning algorithms on unemployment rates.

\section{REFERENCES}

[1] "Unemployment, total (\% of total labor force) (modeled ILO estimate) | Data." [Online]. Available: https://data.worldbank.org/indicator/SL.UEM.TOTL.ZS. [Accessed: 27-Oct-2018].

[2] J. Amani, "Prevalence of, and Factors Associated with, Unemployment among Graduates: Evidence from Tanzania," Afr. Educ. Rev., vol. 14, no. 3-4, pp. 230244, 2017.

[3] "Saudi Arabia Unemployment rate - Economy." [Online]. Available: https://www.indexmundi.com/saudi_arabia/unemployme nt_rate.html. [Accessed: 27-Oct-2018].

[4] gad, "Unemployment rate," General Authority for Statistics, 18-Dec-2016. [Online]. Available: https://www.stats.gov.sa/en/820. [Accessed: 27-Oct2018].

[5] G. C. Dimian, L. S. Begu, and J. Jablonsky, "Unemployment and labour market mismatch in the European Union Countries," Zb. Rad. Ekon. Fak. U Rijeci Časopis Za Ekon. Teor. Praksu, vol. 35, no. 1, pp. 13-44, 2017.

[6] gad, "General authority for statistics, Kingdom of Saudi Arabia," General authority for statistics, Kingdom of Saudi Arabia, 18-Dec-2016. [Online]. Available: https://www.stats.gov.sa/ar/820. [Accessed: 03-Nov2018].

[7] P. Mncayi and S. H. Dunga, "Career choice and unemployment length: A study of graduates from a South African university," Ind. High. Educ., vol. 30, no. 6, pp. 413-423, 2016.

[8] M. Hedayat, S. M. Kahn, and J. Hanafi, "Factors affecting the unemployment (rate) of female art graduates in Iran," Educ. Res. Rev., vol. 8, no. 9, pp. 546-552, 2013.
[9] A. Şahin, J. Song, G. Topa, and G. L. Violante, "Mismatch unemployment," Am. Econ. Rev., vol. 104, no. 11, pp. 3529-64, 2014.

[10] P. Restrepo, "Skill Mismatch and Structural Unemployment," Mass. Inst. Technol. Job Mark. Pap., 2015.

[11] K. Liu, K. G. Salvanes, and E. Ø. Sørensen, “Good skills in bad times: Cyclical skill mismatch and the long-term effects of graduating in a recession," Eur. Econ. Rev. vol. 84, pp. 3-17, May 2016.

[12] S. Joshua, D. E. Azuh, and F. O. Olanrewaju, "University-Industry Collaboration: A Panacea to Graduate Unemployment in Nigeria," Joumal Manag. Res., vol. 7, no. 1, pp. 17-25, 2015.

[13] M. I. M. Razak, I. Ahmad, and G. De Mello, Factors Influencing Unemployment among Graduates in Malaysia. LAP LAMBERT Academic Publishing, 2014.

[14] B. Herz and T. Van Rens, "Accounting for mismatch unemployment," 2018.

[15] H. Erken, E. van Loon, and W. Verbeek, "Mismatch on the Dutch labour market in the Great Recession," Econ. vol. 163 , no. 4, pp. 435-459, 2015.

[16] S. Flisi, V. Goglio, E. C. Meroni, M. Rodrigues, and E. Vera-Toscano, "Measuring occupational mismatch: overeducation and overskill in Europe-Evidence from PIAAC," Soc. Indic. Res., vol. 131, no. 3, pp. 1211 1249,2017

[17] [H.-F. Ho, "Matching university graduates' competences with employers' needs in Taiwan," Int. Educ. Stud., vol 8, no. 4, p. 122, 2015.

[18] R. W. McQuaid and C. Lindsay, "The "employability gap': long-term unemployment and barriers to work in buoyant labour markets," Environ. Plan. C Gov. Policy, vol. 20, no. 4, pp. 613-628, 2002

[19] W. Qayyum and R. Siddiqui, "Causes of Youth Unemployment in Pakistan [with Comments]," Pak. Dev. Rev., pp. 611-621, 2007.

[20] W. Baah-Boateng, "The youth unemployment challenge in Africa: What are the drivers?," Econ. Labour Relat. Rev., vol. 27, no. 4, pp. 413-431, 2016

[21] J. K. Brueckner and Y. Zenou, "Space and unemployment: The labor-market effects of spatial mismatch," J. Labor Econ., vol. 21, no. 1, pp. 242-262, 2003.

[22] N. Arumugam, X. Thayalan, L. C. Dass, and M. Maniam, "Unemployment among graduate nurses in Malaysia: a case study," Asian Soc. Sci., vol. 10, no. 9 , p. 227,2014

[23] Z. Othman et al., "Undergraduate Awareness and Readiness Towards Employability: The Significance of English,” Br. J. Arts Soc. Sci., vol. 2, no. 2, pp. 122-142, 2011.

[24] J. A. Birchenall, "A competitive theory of mismatch," mimeo, UCSB, 2010.

[25] R. Dias and D. Posel, "Unemployment, education and skills constraints in post-apartheid South Africa," 2007. 
[26] K. Asif, "Factors effecting unemployment: A cross country analysis," Int. J. Acad. Res. Bus. Soc. Sci., vol. 3, no. 1, p. 219, 2013.

[27] J. Amani and R. Sima, "The Status of Career Counselling Services in Higher Learning Institutions in Tanzania," Int. J. Educ. Soc. Sci., vol. 2, no. 8, pp. 18-28, 2015.

[28] I. Marinescu and R. Rathelot, "Mismatch Unemployment and the Geography of Job Search," Am. Econ. J. Macroecon., vol. 10, no. 3, pp. 42-70, Jul. 2018.

[29] W. Groot and H. M. Van Den Brink, "Overeducation in the labor market: a meta-analysis," Econ. Educ. Rev., vol. 19, no. 2, pp. 149-158, 2000.

[30] S. McGuinness and P. J. Sloane, "Labour market mismatch among UK graduates: An analysis using REFLEX data," Econ. Educ. Rev., vol. 30, no. 1, pp. 130-145, 2011.

[31] "Graduate Labor Mismatch in Poland," Pol. Sociol. Rev., vol. 179, no. 3, pp. 413-429, 2012.

[32] O. S. Pitan and S. O. Adedeji, "Skills Mismatch among University Graduates in the Nigeria Labor Market.," Online Submiss., 2012.

[33] H. M. Levin and C. E. Rouse, "The true cost of high school dropouts," N. Y. Times, vol. 25, p. A31, 2012.

[34] H. Levin, C. Belfield, P. Muennig, and C. Rouse, The costs and benefits of an excellent education for all of America's children. Teachers College, Columbia University New York, 2006.

[35] H.-E. Lim and M. M. Mustafa, "EFFECTIVENESS OF INDUSTRIAL TRAINING IN IMPROVING STUDENTS'GENERIC SKILLS,” Int. J. Bus. Soc., vol. 14 , no. 3, p. $368,2013$.

[36] I. Nunez and I. Livanos, "Higher education and unemployment in Europe: an analysis of the academic subject and national effects," High. Educ., vol. 59, no. 4, pp. 475-487, 2010.

[37] P. Joassart-Marcelli and A. Giordano, "Does local access to employment services reduce unemployment? A GIS analysis of one-stop career centers," Policy Sci., vol. 39, no. 4, pp. 335-359, 2006.

[38] J. Nie and E. Struby, "Would active labor market policies help combat high US unemployment?," Econ. Rev.-Fed. Reserve Bank Kans. City, p. 35, 2011.

[39] M. Siriwardena, D. Amaratunga, C. Malalgoda, and M. Thayaparan, "Addressing the construction labour market skills mismatch through lifelong learning in higher education institutions," 2011.

\section{APPENDIX}

\section{STRATEGY USED IN SEARCH ENGINES}

Table 3: Search terms

\begin{tabular}{|c|c|c|}
\hline Unemployment & Mismatch & Demand \\
\hline & Mismatch skills & Demand skills \\
\hline & $\begin{array}{c}\text { Educational } \\
\text { mismatch }\end{array}$ & Supply skills \\
\hline & Skills gap & \\
\hline
\end{tabular}

\subsection{ERIC [October 2018]}

("mismatch" OR "skills mismatch" OR "Educational mismatch" OR "demand mismatch" OR "skills gap" OR "Supply skills") AND ("unemployment")

- $\quad$ Limited results to: Peer -reviewed only

- $\quad$ Published between 2000-2019

\subsection{SAGE [October 2018]}

("Supply AND skills" OR "skills AND mismatch" OR "skills AND gap" OR "Educational AND mismatch" OR mismatch OR "demand AND mismatch" ) AND unemployment

- $\quad$ Limited results to: Research Article

- $\quad$ Published between 2000-2019

- $\quad$ Peer -reviewed only

\subsection{JSTOR [October 2018]}

("mismatch" AND "unemployment") OR ("skills mismatch" AND "unemployment") OR ("supply mismatch" AND

"unemployment") OR ("demand mismatch" AND

"unemployment") OR ("gap skills" AND "unemployment") OR ("Educational mismatch" AND "unemployment")

- $\quad$ Published between 2000-2019

- $\quad$ Peer -reviewed only

\subsection{Semantic Scholar [October 2018]}

(("mismatch" OR "skills mismatch" OR "Educational mismatch" OR "demand mismatch" OR "skills gap" OR "Supply skills") AND ("unemployment"))

- $\quad$ Published between 2000-2019

- $\quad$ Peer -reviewed only

\subsection{Springer [October 2018]}

((mismatch OR skills mismatch OR Educational mismatch OR demand mismatch OR skills gap OR Supply skills) AND (unemployment))

- Limited results to: Peer -reviewed only, Article, English

- $\quad$ Published between 2000-2019 